\title{
Estado Capitalista, Trabalho Docente e Educação A Distância
}

\author{
Mariana Novais Vieira \\ Eucídio Pimenta Arruda
}

\section{RESUMO}

O presente artigo tem como objetivo analisar a configuração do Estado capitalista na atualidade e as consequências daí decorrentes para as relações de trabalho, especificamente, para o trabalho docente nas universidades públicas, a partir da política de expansão do ensino superior através da Educação a Distância (EaD), com a institucionalização do Sistema Universidade Aberta do Brasil (UAB). Para tanto, assume como suporte teórico-metodológico o materialismo histórico e aborda a configuração atual do Estado capitalista, que a partir dos anos de 1990 passou a seguir uma tendência gerencial, em consonância com os pressupostos do projeto político neoliberal da Terceira Via. O avanço das Tecnologias da Informação e da Comunicação (TIC) no campo educacional, principalmente com a difusão da modalidade da $\mathrm{EaD}$, é resultado de uma concepção de Estado e de uma forma de funcionamento da política educacional defendida pelo bloco no poder, independentemente das implicações negativas que possa causar sobre os processos de trabalho e de formação humana.

Palavras-chave: Estado capitalista. Trabalho docente. Ensino superior. Educação a Distância.

\section{INTRODUÇÃO}

O presente artigo pretende analisar a configuração do Estado capitalista na atualidade, assim como as implicações daí advindas para as relações de trabalho, em especial para o trabalho docente nas universidades públicas brasileiras, a partir da política de expansão do ensino superior, através da Educação a Distância (EAD), uma vez que novas relações de trabalho são estabelecidas com a institucionalização da Universidade Aberta do Brasil (UAB).

Doutoranda em

Educação pela

Universidade

Federal de Minas

Gerais (UFMG), na

Linha de Pesquisa

Política, Trabalho e

Formação Humana,

sob orientação do

professor Eucídio

Pimenta Arruda.

Bolsista CAPES

e professora da

educação básica

em Juiz de Fora/

MG.

Doutor em

Educação pela

Universidade

Federal de Minas

Gerais (UFMG);

professor da

Faculdade de

Educação da

UFMG, na área de

Políticas Públicas

em Educação e

Tecnologias de

Informação e

Comunicação.

Atualmente, é

coordenador

do Sistema

Universidade

Aberta do Brasil

(UAB) na UFMG. 
Para tanto, este trabalho assume como suporte teórico-metodológico o materialismo histórico e aborda a configuração do Estado capitalista desde a Segunda Guerra Mundial até os anos do neoliberalismo da Terceira Via, período em que o Estado incorpora o modelo gerencial de administração, a partir de 1990. Nesse contexto, novas relações de trabalho são estabelecidas, especialmente, para o trabalho docente no ensino superior, devido à inserção das Tecnologias da Informação e da Comunicação (TIC) no campo educacional, por meio da EAD.

\section{PRESSUPOSTOS TEÓRICO-METODOLÓGICOS}

A opção teórico-metodológica assumida neste trabalho é pelo materialismo histórico, que pressupõe a contextualização do fenômeno ao momento histórico, econômico e social, ou seja, corresponde à análise da dimensão da totalidade, da realidade como um todo estruturado e dialético.

O materialismo histórico não é um método de redução da realidade, mas sim de reprodução da realidade no plano teórico, por meio de diferentes mediações realizadas pela atividade humana com auxílio de categorias de análises, que emergem da dinâmica do mundo real. Esse método permite compreender as manifestações sociais (políticas, econômicas, educacionais etc.) como atividade prática e objetiva dos homens e mulheres reais, organizados em um tempo histórico e em uma sociedade (KOSIK, 1976).

Portanto, “o método está vinculado a uma concepção de realidade, de mundo e vida no seu conjunto. Constitui-se numa espécie de mediação do modo de aprender, revelar e expor a estruturação, o desenvolvimento e a transformação dos fenômenos sociais" (FRIGOTTO, 1987, p.77).

O caminho teórico-metodológico percorrido viabilizou abordar conceitos a respeito do Estado, buscando uma compreensão crítica da realidade, assim como a apreensão do fenômeno em estudo no conjunto das relações sociais, permeada por contradições.

\section{A CONFIGURAÇÃO DO ESTADO CAPITALISTA}

O sistema capitalista de produção da existência humana, em função de sua constituição orgânica contraditória, demonstra ser um sistema que vive crises, mais ou 
menos intensas, devido à dinâmica das relações sociais e de poder constituídas em cada momento histórico nas diferentes formações sociais.

As crises têm uma mesma origem, com uma materialidade específica, "a crise é um elemento constituinte, estrutural, do movimento cíclico da acumulação capitalista, assumindo formas específicas que variam de intensidade no tempo e no espaço" (FRIGOTTO, 2003, p.62). As medidas de superação das crises são processadas na dinâmica das relações sociais, envolvendo reorganização do processo produtivo em crise, mudanças nos procedimentos de gestão da força de trabalho e redefinição das relações de poder por meio de diferentes mecanismos políticos.

No período imediato à Segunda Guerra Mundial, as medidas de superação da crise se intensificaram, sobretudo nos países da Europa ocidental. Tais medidas, iniciadas nos Estados Unidos a partir da reorganização das relações sociais, com repercussões importantes em países da Europa ocidental abalados pelos efeitos da guerra, resultaram na criação de um novo modelo de Estado - o chamado Estado de bem-estar social (welfare state) -, que contou com políticas sociais para minimizar as desigualdades e viabilizar o consumo em massa da produção em grande escala.

A partir da segunda metade dos anos 1970, esse padrão de desenvolvimento, centrado num Estado com muitas funções econômicas e sociais, passou a ser questionado por setores da burguesia inconformados com a desaceleração do ritmo de crescimento econômico. Esses setores passaram a defender novas referências para ordenamento da aparelhagem estatal, tanto nas questões sociais quanto nas de ordem econômica. Defendiam a retomada de princípios liberais para orientar as sociedades capitalistas modernas, valorizando o mercado como centro da atividade vital, marcando, assim, o encerramento da "era de ouro do capital" (HOBSBAWM, 1995).

Com base em "novas" ideias sobre Estado, economia, política e educação, as forças burguesas, por meio de mecanismos de força e de consenso, foram estabelecendo referências importantes para reordenar as bases do padrão de sociabilidade. O pacto em torno do modelo de Estado de bem-estar foi rompido e com ele novas referências ganharam espaço, instruindo, não sem resistência, o novo papel das classes nas relações sociais e também o modo de ser de cada classe.

Nesse contexto, o ideário neoliberal foi confirmado como a base ideológica do caminho alternativo de recuperação econômica e de edificação da nova sociabilidade. As referências desse projeto consideraram a suposta superioridade do mercado sobre 
o Estado como um fato; a necessidade de uma interferência mínima do Estado sobre as questões sociais

- entre elas a educação - como um princípio; e o aumento da produtividade do trabalho como uma necessidade.

Friedrich Hayek foi um dos principais formuladores e articuladores contra o modelo de Estado de bem-estar. Difusor do projeto neoliberal, Hayek defendia o mercado no centro das relações sociais; a individualidade como marca da ação humana; e a liberdade como princípio ordenador das escolhas humanas.

Contudo, a proposta de Estado mínimo, defendido pelo neoliberalismo ortodoxo, mostrou seus limites, uma vez que seria pouco eficiente em relação às funções do aparelho de Estado e à organização da sociedade civil, o que levariam a problemas na coesão social e no ordenamento da sociabilidade, especificamente para a produtividade da força de trabalho (MARTINS, 2011).

Para tanto, buscou-se a elaboração de um projeto político que seria um caminho alternativo entre os ideais da social-democracia clássica e as formulações do neoliberalismo ortodoxo, sendo denominado de neoliberalismo da Terceira Via, no qual o aparelho de Estado incorpora o modelo gerencial de administração, configurando-se em Estado regulador, e a sociedade civil converte-se em espaço da colaboração social.

Assim, nos anos 1990, um novo projeto foi apresentado como referência para reordenar as relações sociais e, consequentemente, o Estado, já que o modelo neoliberal ortodoxo demonstrou-se incapaz de assegurar uma estabilidade da economia mundial. Esse projeto foi sistematizado por Antonhy Giddens (2001) a partir dos pressupostos da atualização da agenda da social-democracia em nível mundial. Tratase de um projeto que visa estabelecer um modelo capitalista de face mais humanizada.

A política neoliberal da Terceira Via é baseada numa nova dinâmica: atuação do governo em parceria com organizações de cunho econômico ou social, a fim de fomentar a renovação do desenvolvimento. Trata-se de

\footnotetext{
uma nova sinergia entre os setores público e privado, utilizando o dinamismo dos mercados mas tendo em mente o interesse público. Ela envolve um equilíbrio entre regulação e desregulação, num nível transnacional bem como em níveis nacional e local; e um equilíbrio entre o econômico e o não-econômico na vida da sociedade. (GIDDENS, 2001, p.109-110) .
} 
Tanto para o programa neoliberal da Terceira Via quanto para o neoliberalismo ortodoxo deve ser eliminada toda e qualquer política estatal que incentive a passividade dos indivíduos, que gere obstáculos para a expansão do mercado e que crie dificuldades para o pacto entre capital e trabalho. Assim, o Estado deve ter suas funções alteradas, ao invés de interventor ou ausente, deve se configurar como regulador da economia e da dinâmica social por ser o centro legítimo de poder.

Uma das características do Estado segundo o modelo gerencial, nos termos propostos pela Terceira Via, é o incentivo à incorporação das Tecnologias da Informação e da Comunicação (TIC) na vida social, tanto naquilo que envolve as políticas públicas quanto no que se relaciona aos processos sociais mais gerais.

A defesa de novos modelos tecnológicos e organizacionais, possibilitado pelas TIC, são concebidos como referências para o aumento da eficiência e aumento da produtividade. A ideia de flexibilidade presente nas TIC permite a racionalização do trabalho, a diminuição dos custos e o controle de tipo "não burocrático", princípio político que deve abranger todos os assuntos e temas públicos, segundo esse modelo estatal.

\section{AS RELAÇÕES DE TRABALHO E O TRABALHO DOCENTE NO ESTADO CAPITALISTA}

Ao longo da história, as mudanças políticas e econômicas ocorridas na sociedade trouxeram implicações para a configuração do trabalho. O trabalho é diversificado e alterado no seu conteúdo histórico: as produções que dependiam exclusivamente do trabalho manual passaram a ser feitas por meio de máquinas; os atos de planejar e de executar foram cindidos, novas exigências comportamentais e intelectuais foram definidas.

É preciso considerar que o trabalho é condição básica para a vida humana e é através dele que o ser torna-se social. Com o trabalho o homem exerce influência sobre a natureza de modo intencional e planejado, o que o diferencia dos demais animais (ENGELS, 2004).

$\mathrm{Na}$ sociedade capitalista, o processo de trabalho torna-se um meio de subsistência e a força de trabalho, uma mercadoria. Isso faz com que o trabalho tornese um meio e não uma necessidade fundamental de realização humana. O resultado 
disso é expresso no estranhamento e, também, na alienação do trabalhador, o que inibe a realização da omnilaterialidade humana, ou seja, o desenvolvimento do ser na sua totalidade, na sua integridade. Para Antunes (1997), há uma tendência geral no capitalismo pela forma como o trabalho se realiza: "o trabalhador repudia o trabalho; não se satisfaz, mas se degrada; não se reconhece, mas se nega" (ANTUNES, 1997, p.125).

Nesse sentido, ao mesmo tempo em que o trabalho é considerado a condição básica para a vida humana, também promove a alienação humana, sendo, portanto, uma unidade contraditória. Conforme Antunes:

\begin{abstract}
se, por um lado, podemos considerar o trabalho como um momento fundante da vida humana, ponto de partida do processo de humanização, por outro lado, a sociedade capitalista o transforma em trabalho assalariado, alienado, fetichizado. O que era uma finalidade central do ser social converte-se em meio de subsistência. A "força de trabalho" (conceitochave em Marx) torna-se uma mercadoria, ainda que especial, cuja a finalidade é criar novas mercadorias e valorizar o capital. Converte-se em meio e não em primeira necessidade de realização humana. (ANTUNES, 2004, p.8).
\end{abstract}

Isso significa ultrapassar a noção de trabalho no capitalismo concentrado como pura negatividade ou como pura positividade. Dessa forma, o trabalho passa a ser compreendido como uma unidade contraditória indivisível entre positividade e negatividade, já que produz tanto a libertação do ser humano da sua condição animalesca (positividade), transformando-o em ser social, quanto produz sua degradação (negatividade), por meio da alienação (FRIGOTTO, 2009).

De acordo com Marx (2004a), o processo de trabalho é uma atividade orientada para produzir valores de uso que se convertem em valores de troca. $\mathrm{O}$ valor de uso é aquilo que resulta do trabalho para satisfazer as necessidades humanas. Ao produzir valores de uso, o trabalho é considerado material. Na medida em que o resultado da força de trabalho ultrapassa o plano do atendimento das necessidades do trabalhador, assumindo a forma mercadoria, converte-se em valor de troca. Nas relações capitalistas, o processo de trabalho gera mais-valia, o que significa exploração, já que para se obter a mais-valia, prolonga-se ou intensificase a jornada de trabalho do trabalhador e não se paga pelas horas a mais trabalhadas, também chamada de "horas de sobretrabalho". Denomina-se "mais-valia ou lucro, aquela parte do valor total da mercadoria em que se incorpora o sobretrabalho, ou trabalho não remunerado" (MARX, 2004b p.77). 
No trabalho imaterial a questão é mais complexa, pois o resultado final não assume uma forma material, um valor de uso. Em outras palavras, o trabalho imaterial não se expressa no objeto físico que pode ser manipulado. Com isso, embora necessário para a reprodução ampliada do capital, o trabalho torna-se improdutivo, isto é, não produz imediatamente o valor de uso e nem valor de troca, sendo difícil precisar a geração de mais-valia.

É interessante ressaltar que a distinção entre trabalho produtivo e improdutivo é, somente, uma maneira de especificar o trabalho na dinâmica da sociedade capitalista. É a relação que se estabelece com o trabalho e não o conteúdo que o define como produtivo ou improdutivo. Nesse sentido, "trabalho produtivo não é senão expressão sucinta que designa a relação integral e o modo pelo qual se apresentam a força de trabalho e o trabalho no processo capitalistas de produção" (MARX, 2004c, p.131).

Assim, um mesmo trabalho pode ser imaterial e produtivo e, também, imaterial e improdutivo, como é o caso do trabalho docente. O professor da rede privada exerce um trabalho produtivo, pois gera mais-valia para os proprietários dos estabelecimentos de ensino; mas este mesmo professor, atuando no setor público, exerce um trabalho improdutivo. Em ambas as formas o trabalho pode ser qualificado de imaterial.

O resultado final do trabalho docente, que é o ensino, não atinge uma forma definida ao final do processo, sendo, portanto, imaterial, pois seu valor de uso acontece ao longo do processo e não se transforma em valor de troca. O que é ensinado ao aluno passa a ter um valor indireto diante de outros tipos de trabalho material, isto é, o conhecimento ensinado pelo professor e apropriado pelo aluno não é algo que se aplica imediatamente, mas sim mediatamente no seu trabalho futuro (BOMFIM, 2010).

Consideramos, assim como Frigotto (2009), que tanto os professores da rede pública quanto os professores da rede privada - mesmo o primeiro exercendo um trabalho imaterial e improdutivo e, o segundo, um trabalho imaterial e produtivo - são explorados. A diferença central está nas mediações em que se processa a exploração. Enquanto a exploração dos professores do setor privado é direta, seguindo a forma clássica, no caso dos professores do setor público, a exploração se faz pelas intermediações do aparelho de Estado e das políticas públicas, envolvendo o controle sobre o fundo público. A exploração dos professores do setor público significa, em 
geral, uma economia do fundo público, algo que passa a ser apropriado por diferentes meios pela classe empresarial.

No contexto capitalista, o trabalho improdutivo é submetido ao processo de exploração, mesmo que não haja extração direta da mais-valia, nada escapa a ordem do capital. Portanto, defendemos que, no processo histórico, mesmo o trabalhador assalariado do setor público, que não produz valor de troca, torna-se também um ser explorado e submetido aos mesmos princípios da exploração que envolve o trabalho concreto. Como resultado, esse trabalhador vive os efeitos dramáticos diretos/indiretos da exploração capitalista em sua especificidade.

A relação contratual baseada no assalariamento é uma forma de relação de produção especificamente capitalista, independente se o trabalhador exerce ou não trabalho produtivo, seja vinculado às agências da aparelhagem estatal ou empresas de ensino. Marx (2004c) defende que

com o desenvolvimento da produção capitalista todos os serviços se transformaram em trabalho assalariado, e todos os seus executantes em assalariados, tendo, pois, essa característica em comum com o trabalhador produtivo, leva tanto mais à confusão entre uns e outros porquanto fenômeno característico da produção capitalista, e por ela gerado. Ademais, dá aos apologistas ocasião para converter o trabalhador produtivo, pelo fato de ser assalariado, em trabalhador que simplesmente troca seus serviços (isto é, o trabalho enquanto valor de uso) por dinheiro. Dessa forma, passam felizes por alto sobre a diferença específica desse "trabalhador produtivo" e a produção capitalista como produção de mais-valia, como um processo de autovalorização do capital, cujo único instrumento (agency), a ele incorporado, é o trabalho vivo. Um soldado é trabalhador assalariado, recebe soldo, mas nem por isso é trabalhador produtivo. (MARX, 2004c, p.130).

Então, apesar de os trabalhadores docentes do setor público exercerem um trabalho improdutivo, também passam pelo processo de exploração, deixando de controlar o seu próprio trabalho. Isso significa que esses trabalhadores também sofrem o processo de exploração, pois aquilo que não se paga na forma salário transforma-se em processo de valorização do fundo público, geralmente servindo para financiar a valorização do capital em seu conjunto.

Desse modo, consideramos que as relações sociais capitalistas, ao definirem a lógica de funcionamento da produção, definem, também, as relações de trabalho, levando-as, no contexto atual, a novas formas de exploração, precarização e intensificação, independente do trabalho ser produtivo ou improdutivo. Com efeito, o trabalho docente, apesar de sua especificidade, também responde a essa dinâmica, algo que pode gerar o processo de estranhamento e levar à alienação (BOMFIM, 2010). 
O trabalho frente à crise atual do capitalismo, iniciada nos anos 1970 e caracterizada pelo reordenamento econômico e pela reforma do Estado, têm sofrido profundas mudanças, sendo marcada pela precarização, intensificação e novas formas de exploração.

Com a mundialização da economia e o avanço tecnológico surge o modelo de acumulação flexível (HARVEY, 1998), marcada pela flexibilidade dos processos de trabalho, dos mercados, dos produtos e dos padrões de consumo, em detrimento da rigidez dos padrões fordistas. Isso promove uma reestruturação produtiva, com aumento do desemprego, de contratos temporários, de subcontratação e de atividades autônomas (BOMFIM, 2010).

Dentre os efeitos para a dinâmica organizacional do trabalho no âmbito da reestruturação produtiva, caracterizada pela acumulação flexível, é interessante considerar:

(1) a introdução de novas tecnologias e, em muitos setores, a decorrente desvalorização geral da força de trabalho, incluindo o aumento do controle do processo de trabalho; (2) o surgimento de novas formas de organização do trabalho, com contratos mais flexíveis, destacando-se o uso do tempo de trabalho parcial, temporário ou subcontratado; e (3) o ataque ao salário real e ao poder dos sindicatos organizados, o que, somado à eliminação de muitos direitos sociais e trabalhistas anteriormente conquistados pela sociedade, tem levado à crescente precarização do trabalho e da vida. (MANCEBO; MAUÉS; CHAVES, 2006, p.40).

O bloco no poder ${ }^{1}$ vem ordenando as políticas econômicas e sociais de modo a intensificar, precarizar e determinar novas formas de exploração do processo de trabalho. Assim, o Estado capitalista, para garantir minimamente o acesso aos direitos sociais, exerce um processo de focalização das políticas sociais, descentralizando suas responsabilidades para empresas ou organizações sem fins lucrativos, intensificando e apresentando novas formas de exploração do trabalho.

O conjunto de transformações por qual passa o processo de trabalho no atual contexto capitalista é denominado por Antunes (2009) como nova morfologia do trabalho, marcada por novas modalidades precarizadas de trabalho. Tais modalidades são presenciadas no trabalho docente, principalmente a partir dos anos 1990, década

\footnotetext{
${ }^{1} \mathrm{O}$ constructo "bloco no poder" possibilita compreender a unidade e a diversidade de interesses de classes, presentes numa aliança política, assumidas pelas instâncias de exercício de poder no aparelho de Estado, na forma de governo. O conceito de bloco no poder permite revelar como as frações de classe se organizam nas instâncias da aparelhagem estatal e como os interesses distintos ou mesmos contraditórios entram em relação no interior dos governos e suas repercussões nas funções do Estado. (POULANTZAS, 2000).
} 
da reforma educacional brasileira em todos os níveis. Isso revela uma nova forma de regulação gerencialista do Estado na educação brasileira.

\title{
O TRABALHO DOCENTE NO ENSINO SUPERIOR: A EDUCAÇÃO A DISTÂNCIA EM FOCO
}

As reformas educacionais brasileiras dos anos 1990 responderam às novas demandas do mercado de trabalho, estando em conformidade com a política de acumulação flexível e com as políticas das agências financeiras internacionais. Isso gerou consequências para o trabalho docente em todos os níveis de ensino, em especial para o ensino superior, diante da política de expansão desse nível de ensino por meio da EaD.

As relações sociais no Brasil entre os anos finais do século XX e anos iniciais do novo século produziram mudanças em relação à educação e ao trabalho docente. Nesse contexto, os pressupostos neoliberais da Terceira Via ganharam força, com o novo sistema de acumulação flexível, demarcando formas precárias e intensificadas de trabalho e aumento de desemprego, como demonstram Sguissardi e Silva Júnior (2009):

\begin{abstract}
Nesta forma de acumulação condensam-se as formas pretéritas e atuais de exploração do trabalho, atualizadas por novas e eficientes formas de controle e valorização do capital, por sua vez representativas da mais relevante inovação do capitalismo para manter sua produtividade e diminuir seu custo (o trabalho vivo). Como consequência, ela realiza e amplifica o desemprego, reorganiza o mercado de trabalho material e imaterial e desestrutura as formas de representação da classe trabalhadora, isso tudo em benefício do capital. (SGUISSARDI; SILVA JÚNIOR, 2009, p.60).
\end{abstract}

Se de um lado o Estado gerencial, em consonância com os pressupostos neoliberais da Terceira Via, demarca formas precárias e intensificadas de trabalho, por outro, também apresenta novas formas de exploração. O processo de intensificação do trabalho docente é apresentado em estudos como o de Sguissardi e Silva Júnior (2009), que enfatizam a intensificação do trabalho dos professores das federais, a partir da expansão da pós-graduação nos últimos anos. De outro lado, novas formas de exploração são realizadas, como exemplo o trabalho docente na UAB, no qual bolsistas 
exercem o trabalho em conjunto com os professores das universidades públicas, assumindo a função de tutor, sem as devidas condições trabalhistas (MILL, 2006).

A presença do tutor traz modificações claras para a prática docente na $\mathrm{UAB}, \mathrm{o}$ que resulta numa relação pedagógica diferenciada. Por isso, diferentes formulações são propostas para designar os profissionais envolvidos na EaD. Dentre elas podemos citar "professor coletivo" (BELLONI, 2001) e "polidocência" (MILL, 2006).

$\mathrm{O}$ investimento neoliberal na educação superior se explicita na crescente privatização interna das universidades públicas; na expansão do ensino a distância; na abertura de novas vagas no ensino privado; e nas avaliações externas baseadas em critérios quantitativos. Tais situações afetam diretamente o trabalho docente.

No que se refere ao avanço da modalidade a distância, mediada pelas TIC, fazse necessário analisar até que ponto a inserção das TIC no campo educacional interfere no processo de trabalho docente. A EAD na educação superior brasileira, consolidouse com a institucionalização do Sistema $U A B$, dirigida à formação de professores.

Com a UAB, um novo quadro político delineia-se, já que foram estabelecidas novas regulamentações de funcionamento dos cursos; criaram-se novas funções no processo de ensino e aprendizagem, assim como novas relações de trabalho e institucionais; e instituiram-se diferenciações salariais, devido à distribuição de bolsas para os professores participantes do programa (OSÓRIO; GARCIA, 2011).

A EAD passou a ocupar lugar estratégico na política educacional para o ensino superior, sendo tratada pelos organismos internacionais como uma possibilidade de expansão do acesso ao ensino superior, com o objetivo de solucionar os problemas educacionais. Isso trouxe novas relações para o trabalho docente nas universidades públicas, fazendo com que professores assumam novas responsabilidades. Portanto, as políticas de educação superior do Estado capitalista nos anos do neoliberalismo da Terceira Via buscam otimizar os gastos, com aumento da produtividade docente.

Dessa maneira, o mercado de trabalho é reorganizado e o processo de intensificação e precarização do trabalho docente evidenciado. Isso é perceptível na própria atuação do professor na EAD. Segundo Barreto (2004),

Esse paradigma é constituído pela substituição tecnológica e pela racionalidade instrumental, está escrito na 'flexibilização', especialmente na precarização do trabalho docente, sendo coerente com a lógica do mercado: quanto maior a presença da tecnologia, menor a necessidade do trabalho humano. Em outras palavras, prevê cada vez menos professores e mais alunos, sob alegação de que o desempenho dos últimos depende 
menos da formação dos primeiros e mais dos materiais utilizados. (BARRETO, 2004, p.1189).

O sistema UAB começou a se concretizar a partir da promulgação do Decreto $\mathrm{n}^{\circ}$ 5.622, de 19 de Janeiro de 2005 (BRASIL, 2005) que regulamenta o artigo 80 da LDB nº 9.394/96 (BRASIL, 1996), dando ordenamento legal à EAD e estabelecendo diretrizes para a oferta de cursos na educação básica e superior, bem como na pósgraduação.

A UAB, especificamente, foi regulamentada pelo Decreto $\mathrm{n}^{\circ} 5.800$, de 8 de junho de 2006 (BRASIL, 2006), com a finalidade de expandir e interiorizar cursos e programas de educação superior, constituindo-se como um sistema nacional público de formação de professores a distância. Apresenta cinco eixos fundamentais, que sinalizam para a expansão e consolidação de uma nova política de formação de professores no país:

- Expansão pública da educação superior, considerando os processos de democratização e acesso;

- Aperfeiçoamento dos processos de gestão das instituições de ensino superior, possibilitando sua expansão em consonância com as propostas educacionais dos estados e municípios;

- Avaliação da educação superior a distância tendo por base os processos de flexibilização e regulação implantados pelo MEC;

- Estímulo à investigação em educação superior a distância no País;

- Financiamento dos processos de implantação, execução e formação de recursos humanos em educação superior a distância. (BRASIL, 2006).

Nesse sentido, a UAB passou a ser um dos principais meios das políticas de expansão de matrículas na educação superior, bem como passou a representar um sistema nacional de $\mathrm{EaD}$, consolidando um novo modelo de educação.

\section{CONSIDERAÇÕES FINAIS}

A nova configuração assumida pelo Estado capitalista, com a adoção do projeto político neoliberal da Terceira Via, apresenta novas formas de intensificação, precarização e de exploração do processo de trabalho.

Uma das características da configuração do Estado capitalista brasileiro na atualidade é o predomínio do modelo gerencial, como referência para ordenar as 
políticas e as responsabilidades constitucionais do Estado em relação aos direitos de educação.

As TIC foram introduzidas para alavancar certas ações estatais, principalmente na política educacional, através da $\mathrm{EAD}$, que, em nome do direito social à educação, vem produzindo consequências ainda não percebidas no plano imediato da vida. $\mathrm{O}$ bloco no poder criou mecanismo, talvez, sem precedentes em nossa história, qual seja: ampliou o direito ao acesso à educação superior à custa da exploração do trabalho de professores e tutores.

Se antes, a intensificação, a precarização e a terceirização do trabalho (contratação dos tutores sem vínculo institucional trabalhista) eram marcas do setor privado, a UAB exemplifica que tal processo tornou-se realidade no setor público.

A afirmação do direito social à educação não pode ser operada na negação do direito social ao trabalho digno. Isso tende a invalidar as possíveis conquistas sob o ponto de vista econômico-gerencial, em função dos efeitos negativos de médio prazo (qualidade da formação dos discentes em decorrência do estranhamento do trabalho) e de longo prazo (custos do adoecimento docente). Por isso, questiona-se a validade de um modelo em que os professores e tutores arcam com os custos da expansão do ensino superior, por meio da EAD.

Não se trata de questionar a potencialidade da EAD, mas sim inquirir se as bases sociais e fundamentos políticos, ideológicos e financeiros com as quais essa modalidade se desenvolve na atualidade são adequados quando pensamos a condição do ser humano que trabalha.

Portanto, mais do que um processo natural, o avanço das TIC no campo educacional, principalmente com a difusão da modalidade da EAD, é resultado de uma concepção de Estado e de uma forma de funcionamento da política educacional defendida pelo bloco no poder, independentemente das implicações negativas que isso possa causar sobre os processos de trabalho e de formação humana.

\section{REFERÊNCIAS}

ANTUNES, Ricardo. Século XXI: nova era da precarização estrutural do trabalho?. In: ANTUNES, R.; BRAGA, R. (Org.). Infoproletários: degradação real do trabalho virtual. São Paulo: Boitempo, 2009. 
ANTUNES, Ricardo. Adeus ao trabalho?: ensaios sobre as metamorfoses e a centralidade do mundo do trabalho. 4. ed. São Paulo: Cortez. 1997.

BARRETO, Raquel Goulart. Tecnologia e educação: trabalho e formação docente. Educação \& Sociedade, Campinas, v. 25, n. 89, p.1181-120,1set./dez. 2004,

BELLONI, Maria Luíza. Educação a distância. 2. ed. São Paulo: Autores Associados, 2001. p. 79-89.

BOMFIM, Maria Inês do Rego Monteiro. Trabalho docente na escola pública brasileira:as finalidades humanas em risco. In: CIAVATTA, M.; REIS, R. R. (Org.). A pesquisa histórica em trabalho e educação. Brasília: Liber Livro Editora, 2010. p. 89-111.

BRASIL. Decreto $n^{0} 5.800$, de 8 de junho de 2006. Dispõe sobre o Sistema Universidade Aberta do Brasil - UAB. Diário Oficial da União, Brasília, 9 jul. 2006. Disponível em:

$<$ http://www.planalto.gov.br/ccivil_03/_ato20042006/2006/decreto/d5800.htm> Acesso em: 10 jun. 2014.

BRASIL. Decreto ${ }^{0}$ 5.622, de 19 de Janeiro de 2005. Regulamenta o art. 80 da Lei no 9.394, de 20 de dezembro de 1996, que estabelece as diretrizes e bases da educação nacional. Diário Oficial da União, Brasília, 20 dez. 2005. Disponível em: $<$ http://www.planalto.gov.br/ccivil_03/_ato2004-2006/2005/decreto/d5622.htm> Acesso em: 04 jul. 2016.

BRASIL. Lei $n^{\circ}$ 9.394, de 20 de dezembro de 1996. Estabelece as Diretrizes e Bases da Educação Nacional. Brasília: Casa Civil, 1996. Diário Oficial da União, Brasília, 23 dez. 1996. Disponível em: <

http://www.planalto.gov.br/ccivil_03/Leis/L9394.htm> Acesso em: 04 jul. 2016.

ENGELS, Friedrich. Sobre o papel do trabalho na transformação do macaco em homem, 1876. In: ANTUNES, R. A dialética do trabalho: escritos de Marx e Engles. São Paulo: Expressão Popular, 2004.

FRIGOTTO, Gaudêncio. A polissemia da categoria trabalho e a batalha de ideias nas sociedades de classe. Revista Brasileira de Educação, Campinas, v. 14, n. 40, jan./abr. 2009. Disponível em:

$<$ http://www.scielo.br/pdf/rbedu/v14n40/v14n40a14.pdf $>$ Acesso em: 15 jan. 2014.

FRIGOTTO, Gaudêncio. Educação e a crise do capitalismo real. 5 ed. São Paulo: Cortez, 2003.

FRIGOTTO, Gaudêncio. O enfoque da dialética materialista na pesquisa educacional. Vitória: Encontro Regional de Pesquisa Sudeste, 1987.

GIDDENS, Antony. A terceira via: reflexões sobre o impasse político atual e o futuro da social-democracia. 4. ed. Rio de Janeiro: Record, 2001.

HARVEY, David. Condição pós-moderna. 7. ed. Loyola: São Paulo, 1998. 
HOBSBAWM, Eric. Era dos extremos: o breve século XX: 1914-1991. Tradução de Marcos Santarrita. 2. ed. São Paulo: Companhia da Letras, 1995.

KOSIK, Karel. Dialética do concreto. 2. ed. Rio de Janeiro: Paz e Terra, 1976.

MANCEBO, Deise; MAUÉS, Olgaíses; CHAVES, Vera Lúcia Jacob. Crise e reforma do Estado e da Universidade Brasileira: implicações para o trabalho docente. Educar, Curitiba, n. 28, p. 37-53, 2006.

MARTINS, André Silva. O Estado educador: notas para a reflexão. In: ANDRADE, Juarez de; PAIVA, Lauriana Gonçalves de (Org.). As políticas para a educação no Brasil contemporâneo: limites e contradições. Juiz de Fora: UFJF, 2011. p.72-89.

MARX, Karl. Processo de trabalho e processo de valorização. In: ANTUNES, R. A dialética do trabalho: escritos de Marx e Engles. São Paulo: Expressão Popular, 2004a.

MARX, Karl. Salário, preço e lucro. In: ANTUNES, R. A dialética do trabalho: escritos de Marx e Engles. São Paulo: Expressão Popular, 2004b. p. 57-100.

MARX, Karl. Trabalho produtivo e trabalho improdutivo. In: ANTUNES, R. A dialética do trabalho: escritos de Marx e Engles. São Paulo: Expressão Popular, 2004c. p. 125-140.

MILL, Daniel. Educação a distância e trabalho docente virtual: sobre tecnologia, espaços, tempos, coletividade e relações sociais de sexo na Idade Mídia. Tese (Doutorado em Educação) - Programa de Pós-Graduação em Educação, Universidade Federal de Minas Gerais, Belo Horizonte, 2006.

OSÓRIO, Mara Rejane Vieira; GARCIA, Maria Manuela Alves. Universidade Aberta do Brasil (UAB): (re)modelando o território da formação de professores.

Cadernos de Educação, Pelotas, p. 119-149, jan./abr. 2011. Disponível em: $<$ http://www.ufpel.edu.br/fae/caduc/downloads/n38/05.pdf.> Acesso em: 12 out 2014.

POULANTZAS, Nicos. O Estado, o poder, o socialismo. São Paulo: Paz e Terra, 2000.

SGUISSARDI, Valdemar; SILVA JÚNIOR, João dos Reis Silva. Trabalho intensificado nas federais: pós-graduação e produtivismo acadêmico. São Paulo: Xamã, 2009. 